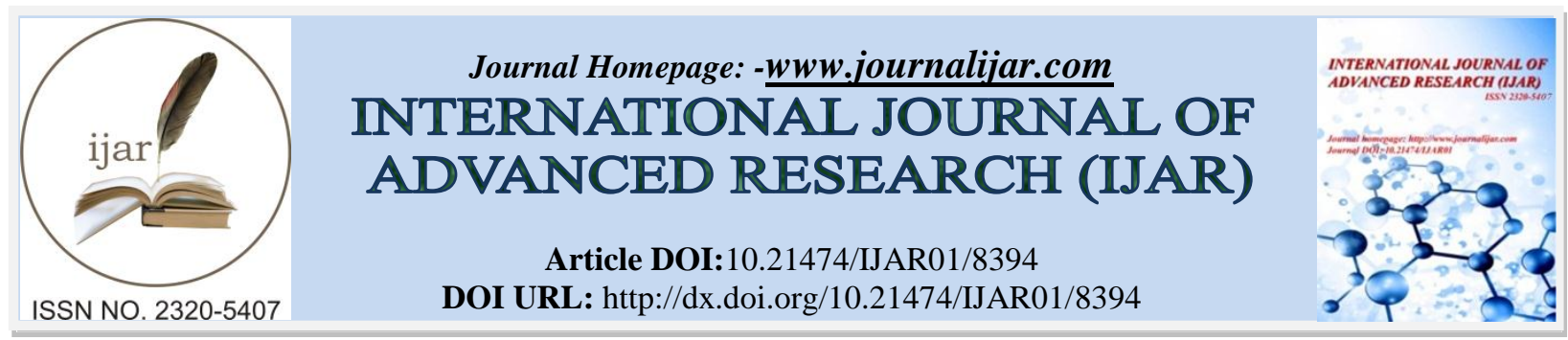

RESEARCH ARTICLE

\title{
ACCESSORY HEAD OF CORACOBRACHIALIS AND ITS CLINICAL USES.
}

\author{
R.Raja Rajeshwari Devi ${ }^{1}$, Hirendra. R. Shah ${ }^{2}$ and Dipali. J.Trivedi ${ }^{3}$. \\ 1. Third Year Resident, Department of Anatomy, B. J. Medical College, Ahmedabad, Gujarat. \\ 2. Additional Professor, Department of Anatomy, B. J. Medical College, Ahmedabad, Gujarat. \\ 3. Professor, Department of Anatomy, B. J. Medical College, Ahmedabad, Gujarat.
}

\section{Manuscript Info}

Manuscript History

Received: 12 November 2018

Final Accepted: 14 December 2018

Published: January 2019

\section{Key words:-}

Coracobrachialis, Struther's ligaments, median nerve, brachial artery.

\begin{abstract}
Coracobrachialis is the most medial of three anterior compartment muscles of arm. In some mammals it is tricipital in origin. The lower head is usually suppressed in man. Sometimes it is represented by a fibrous band, the ligament of Struther's. During our dissection regime of $1^{\text {st }}$ MBBS students in the department of anatomy, BJMC, we observed an accessory head of coracobrachialis on the right side of a male embalmed donated cadaver .The muscle was described as being functionally unimportant. However, the muscle has recently attracted interest with its potential use for contouring the infraclavicular area or covering the exposed axillary vessels specifically in postmastectomy reconstructive operations, muscle transfer for the treatment of paralysis, as a guide for axillary artery access and anaesthetic blockade of the brachial plexus.
\end{abstract}

Copy Right, IJAR, 2017,. All rights reserved.

\section{Introduction:-}

Coracobrachialis is the most medial of three anterior compartment muscles of arm.

It arises from the tip of coracoid process in common with the short head of biceps brachii and inserted by fleshy fibres to the medial border of the middle of the shaft of humerus where the nutrient foramen of the bone is usually located. The muscle is supplied by musculocutaneous nerve, a branch from the lateral cord. It is said that the nerve pierces the muscle and supplies it before piercing. It is a weak flexor of shoulder joint. Coracocobrachialis represents the adductor muscle of arm but such action is insignificant in man. In some mammals it is tricipital in origin. Upper 2 heads are fused to take origin from coracoid process and enclose the musculocutaneous nerve between them. The lower head is usually suppressed in man. Sometimes it is represented by a fibrous band, the ligament of struthers, which extends from an occasional bony projection, the supratrochlear spur, from the anteromedial surface of lower part of the humerus to the medial epicondyle. Median nerve or brachial artery may pass beneath the ligament which compress upon them producing vascular spasm or median nerve palsy ${ }^{2}$. The muscle was described as being functionally unimportant ${ }^{3}$.

However, the muscle has recently attracted interest with its potential use for contouring the infraclavicular area ${ }^{4,7}$ or covering the exposed axillary vessels specifically in postmastectomy reconstructive operations ${ }^{5}$, muscle transfer for the treatment of paralysis, as a guide for axillary artery access and anaesthetic blockade of the brachial plexus ${ }^{4,6}$.

Corresponding Author:-R.Raja Rajeshwari Devi.

Address:-Third Year Resident, Department of Anatomy, B. J. Medical College, Ahmedabad, Gujarat. 


\section{Case report:-}

During our dissection regime of $1^{\text {st }}$ MBBS students in the department of anatomy, BJMC, we observed an accessory head of coracobrachialis on the right side of a male embalmed donated cadaver. Coracobrachialis was arising from the tip of coracoid process of scapula, in between them passed the musculocutaneous nerve. But we observed that few muscle fibres was arising from superficial fibres of coracobrachialis at its insertion and also from medial border of short head if biceps brachii muscle which was running slightly downward and medially and got blended with the medial intermuscular septum. This muscle is called accessory coracobrachialis also called third head of coracobrachialis or coracobrachialis longus. The muscle was $7.5 \mathrm{~cm}$ in length and $0.7 \mathrm{~cm}$ in diameter.

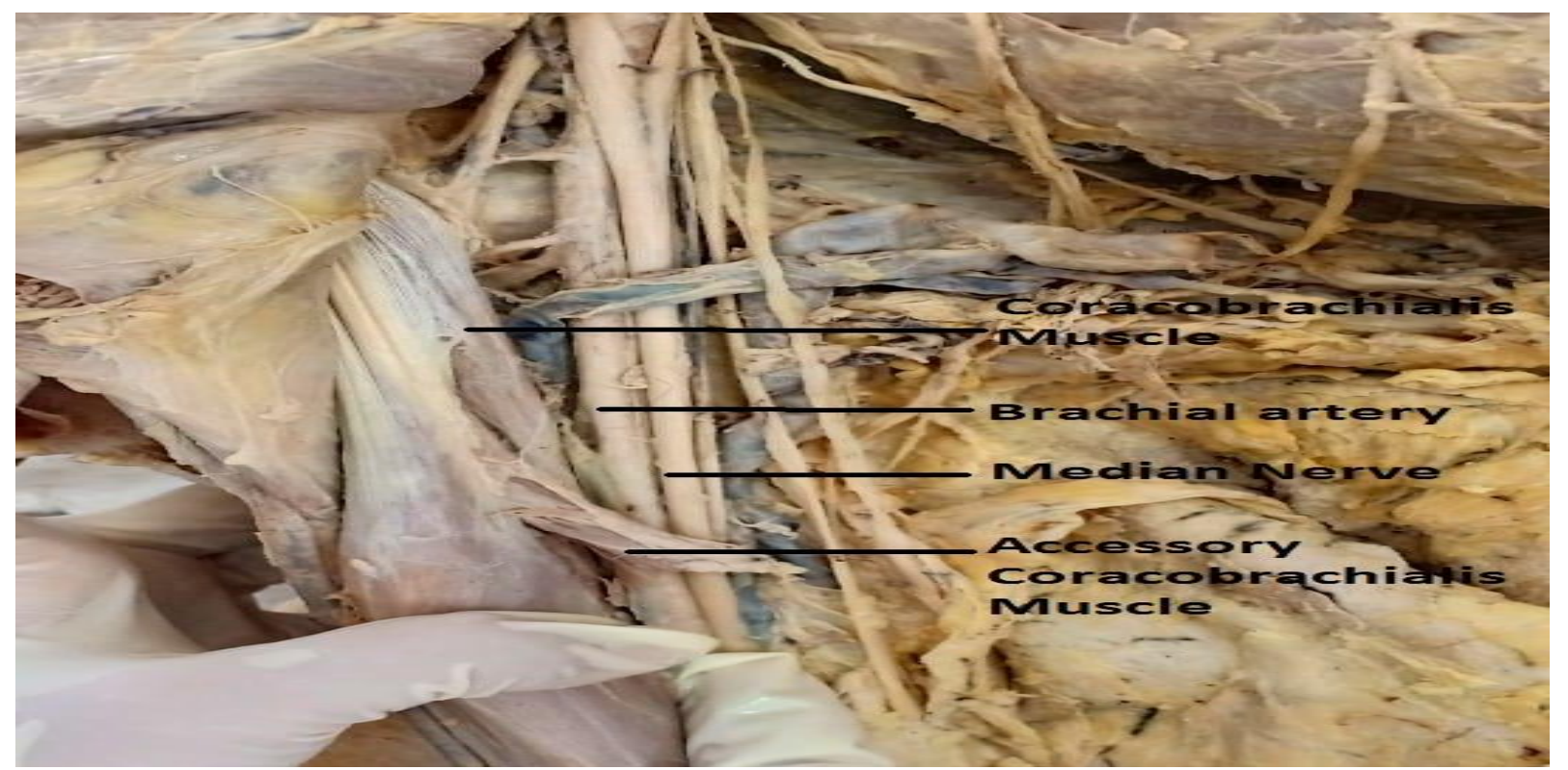

Figure 1:-Showing Coracobrachialis muscle, Accessory belly of Coracobrachialis muscle, Median nerve and Brachial artery.

\section{Discussion:-}

The coracobrachialis muscle is more important morphologically than functionally9.

Three distinct parts of the coracobrachialis muscle are described in amphibians, reptiles, and monotremes:Coracobrachialis brevis (profundus), which is inserted into the humerus superior to tendon of latissimus dorsi, Coracobrachialis medius (proprius), which is inserted into the humerus inferior to tendon of latissimus dorsi, and Coracobrachialis longus (superficialis) or Wood's muscle, which extends inferiorly on the shaft of humerus bridging the median nerve and brachial artery. Some apes and prosimians have coracobrachialis muscle composed of two parts, which is equivalent to coracobrachialis brevis. The coracobrachialis in man is formed of one muscular part that probably represent the persistence of coracobrachialis medius of lower animals or the fusion of two heads of that muscle which are observed in apes and prosimians, trapping the musculocutaneous nerve between them ${ }^{10}$.

The origin of morphological variation of the coracobrachialis may be explained on the basis of the embryogenesis of the muscles of the arm. The intrinsic muscles of the upper limb differentiate in situ from the limb bud mesenchyme of lateral plate mesoderm. At a certain stage of development, the muscle primordia within the different layers of the arm fuse to form a single muscle mass. Thereafter, some muscle primordia disappear through cell death. Failure of muscle primordia to disappear during embryologic development may account for the presence of the accessory belly of coracobrachialis muscle reported in this case ${ }^{11,12}$.

In cats and some monkeys, sometimes the supracondylar process forms an arch that is homologous to the bony arch observed in the inferior part of the humerus. In the cat, this opening is formed completely by an arch of bone leaving and again joining the lower part of medial aspect of the shaft of the humerus ${ }^{7,13,14}$. 
Wood (1867) reported that when the internal brachial ligament is well developed, it may pass entirely superficial to and across the brachial vessels and median nerve, forming an aponerotic opening for them which is known as the supracondylar opening. Occasionally a fibrous strip usually passes from the tendon, near its humeral insertion, to the long head of triceps; occasionally muscular, it is homologue of the dorso-epitrochlearis brachii of apes ${ }^{1,15}$.

Koizumi \& Sakai ${ }^{18}$ found that musculocutaneous nerve pierces coracobrachialis muscle in Chimpanzee, but not in Gorilla or Gibbon.

Tonic contraction of the two heads of the coracobrachialis muscle may have an important role in fixing the tendon of the short head of biceps brachii during the movement of supination of the forearm and flexion of the elbow ${ }^{17}$.

Mesdagh et al $^{25}$ reported a subcoracoid impingement caused by an accessory coracobrachialis treated by simple resection.

The coracoepitrochlearis muscle could also cause confusion when different imaging modalities are used, and it could restrict the abduction of the $\operatorname{arm}^{16}$.

Any injury of ulnar nerve in axilla may hamper the extension of this elbow if the variant belly was supplied by ulnar nerve ${ }^{9}$.

Carpal tunnel syndrome, pronator teres syndrome and anterior interosseous syndrome are three well described entrapment syndromes involving the median nerve or its branches. But compression of the median nerve and brachial artery by accessory muscle of coracobrachialis slips leading to clinical neurovasculopathy has also been reported $^{19,20}$.

These muscles should not be mistaken for tumors on evaluation of computed tomography (CT) and magnetic resonance $(\mathrm{MR})$ imaging $^{24}$.

Coracobrachialis has been used as a transposition flap in deformities of infraclavicular and axillary areas and in postmastectomy reconstruction ${ }^{4,8}$.

It is also used as stabilisation treatment for recurrent dislocation and subluxation of the shoulder joint ${ }^{6}$.

Coracobrachialis has also been used as vascularised muscle graft in the treatment of longstanding fascial paralysis ${ }^{15}$.

A rare case of proximal coracobrachialis tendon rupture with subscapularis tendon rupture and medial dislocation of long head of biceps tendon in an adult after a traumatic anterior shoulder dislocation was also reported ${ }^{22}$.

Coracobrachialis myofascial flap was used recently for management of synovio-cutaneous fistula following rotator cuff repair ${ }^{23}$.

Also there are cases of musculocutaneous nerve schwannoma within coracobrachialis muscle ${ }^{21}$.

\section{References:-}

1. Williams PL, Warwick R, Dyson M, Bannister LH (1989) Gray's Anatomy, 41th ed., Edinburgh: Churchill Livingstone, pp. 821.

2. Datta AK. Essentials of Human Anatomy. 3rd Ed., Kolkata: Current Books International; 2004. pp. 56-59.

3. Nakatani T, Mizukami S, Tanaka S (1997a) Three cases of the musculocutaneous nerve not perforating the coracobrachialis muscle. Acta Anat Nippon, 72: 191-194.

4. Kopuz C, Içten N, Yildirim M. A rare accessory coracobrachialis muscle: a review of the literature. Surg Radiol Anat. 2003; 24(6): 406-410, doi:10.1007/s00276-002-0079-5, indexed in Pubmed: 12652369.

5. Chouke KS: Variation of the coracobrachialis muscle. Anat Rec. 1924, 27:157-161. 10.1002/ar.1090270303

6. Jiang LS, Cui YM, Zhou ZD, Dai LY. (2007) Stabilizing effect of the transferred conjoined tendon on shoulder stability. Knee Surg Sports Traumatol Arthrosc; 15, 800-5.

7. Struthers J. (1854) On some points in the abnormal anatomy of the arm. Br Foreign Med Chir Rev, 14, 224-36. 
8. Hobar PC, Rohrich RJ, Mickel TJ (1990) The coracobrachialis muscle flap for coverage of exposed axillary vessels: a salvage procedure. Plast Reconstr Surg, 85: 801-804.

9. Debalina Maiti, Swagata Bhattacharya. A study on variations of accessory coracobrachialis muscle along with variations of biceos brachii muscle. Int J Anat Var. 2018: 11(2): 66-69.

10. Guha R, Satyanarayana N, Reddy CK. Variant insertion of coracobrachialis muscle morphological significance, embryological basis and clinical importance. J College Med Sci-Nepal. 2010;6:42-6.

11. Ciha' $\mathrm{kR}$. Ontogenesis of the skeleton and intrinsic muscles of the human hand and foot. Adv Anat Embryol Cell Bioll. 1972; 46: 1-194.

12. Grim M. Ultra structure of the ulnar portion of the contrahent muscle layer in the embryonic human hand. Folia Morphol 1972; 20:113-15.

13. Witt CM. The supracondyloid process of the humerus.J Missouri Med Assn 1950; 47:445- 46

14. Kessel L, Rang M. Supracondylar spur of the humerus. J Bone Joint Surg1966; 48(B):765-69.

15. Wood J. On human muscular variations and their relationto comparative anatomy. J Anat Physiol 1867; 1:44-59

16. Bauones S, Moraux A: The accessory coracobrachialis muscle: ultrasound and MR features . Skeletal Radiol. 2015, 44:1273-1278. 10.1007/s00256-015-2153-1

17. Bassett RW, Browne AO, Morrey BF, An KN (1990) Glenohumeral muscle force and moment mechanics in a position of shoulder instability. J Biomech, 23: 405-415.

18. Koizumi M, Sakai T (1995) The nerve supply to coracobrachialis in apes. J Anat, 186: 395-403.

19. Gessini L, Jandolo B, Pietrangeli A. Entrapment neuropathies of the median nerve at and above the elbow. Surg Neurol. 1983; 19: 112- 116.

20. Nakatani T, Tanaka S, Mizukami S. Bilateral four-headed biceps brachii muscles: the median nerve and brachial artery passing through a tunnel formed by a muscle slip from the accessory head. Clin Anat. 1998; 11: 209-212.

21. Jun nishio, takayuki Ueki, masatoshi Naito. Intramuscular schwannoma of the musculocutaneous nerve: an uncommon clinical presentation. Exp Ther Med. 2013: 6(1): 164-166.

22. Bryan M Saltzman, Joshua D Harris, Brian Forsythe. Proximal coracobrachialis tendon rupture, subscapularis tendon rupture and medial dislocation of the long head of biceps tendon in an adult after traumatic anterior shoulder dislocation. Int J Shoulder Surg. 2015: 9(2): 52-55.

23. Zuhlke, Todd A, Wolfort, SeanF. Coracobrachialis myofascial flap. Management of a synovio cutaneous fistula following rotator cuff repair. Annals of plastic surgery. 2012: vol 68 issue 6,p 630-638.

24. Ritika P. Parekh, Sharadkumar P. Sawant, Shaheen Rizvi. Third head of coracobrachialis muscle. International Journal Of Advances In Case Reports, 2017;4(3):148-150.

25. H Mesdagh, C. Maynox, X. Cssagnaud. Accessory coracobrachialis muscle as a cause of anterior impingement syndrome of the rotator cuff in an athlete. European journal of orthopaedic surgery \& traumatology. 2002; vol 12 ; issue 2, pp 96-98. 